\title{
Preface: Economics of groundwater management
}

\author{
Peter Reinelt • Nicholas Brozović • M. Ejaz Qureshi • \\ Petra Hellegers
}

Keywords Groundwater management · Economic efficiency · Economic value · Hydrological modeling . Water supply

\section{Introduction}

Effective management of groundwater resources in a world where high-quality source water is becoming both physically and economically scarcer requires interdisciplinary collaboration among hydrologists, ecologists, engineers, and economists. This theme issue, Economics of Groundwater Management, seeks to further communication and cooperation across disciplines by presenting a collection of economic research articles that demonstrate a broad range of approaches used by economists to integrate hydrologic concepts into economic frameworks.

The theme issue opens with an overview of the economic approach to groundwater management in Qureshi et al. Economists commonly define optimal groundwater management as the rate of extraction by location and time that maximizes the present value of net benefits (after deducting the costs from the gross benefits). Making the best use of limited groundwater resources

Received: 16 April 2012 / Accepted: 21 May 2012

Published online: 14 June 2012

(C) Springer-Verlag 2012

P. Reinelt (-

State University of New York,

280 Central Ave, Fredonia, New York 14063, USA

e-mail: Peter.Reinelt@,fredonia.edu

N. Brozović

University of Illinois at Urbana-Champaign,

1207 S Oak St, Champaign, Illinois 61820, USA

M. E. Qureshi

CSIRO Ecosystem Sciences, Locked Bag 10, Canberra, VIC 3169 , Australia

M. E. Qureshi

Fenner School of Environment and Society, ANU,

Building 48 Linnaeus Way, Canberra, ACT 0200, Australia

P. Hellegers

Wageningen UR, LEI, PO Box 297032502 LS, The Hague,

The Netherlands

requires a conceptual framework that defines best use combined with knowledge of alternate extractive and nonextractive values, the costs of extraction, the hydrological interlinkages between alternative uses, hydrological linkages with surface water, the cost of alternative water sources, and how policy and institutions influence outcomes. Hydrological models of quantity and quality are essential since maximization of net benefits is subject to the hydrological characteristics of the aquifer and related water sources. Incorporation of extraction and application technologies and costs, as well as structural solutions such as artificial recharge, require hydrological and irrigation engineering knowledge. Since economists broadly define benefits to include both extractive and non-extractive values, ecological modeling may be necessary for appropriate valuation. Furthermore, institutional and policy factors influence groundwater value and must be considered in concert with supply and demand.

\section{Gains from optimal management}

Determination of the gains from optimal management of groundwater, as compared to decentralized pumping decisions under a common property regime, remains a central thread through the economic literature of groundwater management (Brown and Deacon 1972; Gisser and Sanchez 1980; Provencher and Burt 1993). Gisser and Sanchez's (1980) finding of limited gains to optimal management under restrictive hydrologic, agronomic, and economic assumptions became known as the GisserSanchez effect and continues to spawn papers to define the limits of its applicability (for a recent review, see Koundouri 2004). Many of the current directions of this research require finding hydrological and economic models with higher spatial resolution and ecological models that can be tractably incorporated into the economic optimization framework.

In an essay here, Katic and Grafton examine the underlying spatial assumptions prevalent in most early economic models of groundwater extraction. They review recent literature on spatially modeled groundwater extraction and present alternative model specifications allowing for both spatial heterogeneity and spatial and endogenous well-location decisions. To assess the potential analytical and policy gains of spatially differentiated dynamic models, they argue for a research agenda that analyzes 
the costs of spatial policy implementation, whether decentralized self-regulation schemes could be effective, the impact of uncertainty on groundwater management designs, and institutional design questions when spatial models straddle regional and national boundaries.

Saak and Peterson present a theoretical analysis of the potential roles of user size (in this case, small and large farmers that irrigate using groundwater) and income inequality in affecting the welfare impacts of common property groundwater extraction. They show that with heterogeneous users, the common property resource problem results in spatial and dynamic inefficiencies because of income impacts both between farmers and across time periods. Their results demonstrate the potential importance of the distribution of water-user characteristics in determining the economic impacts of ongoing aquifer depletion.

Esteban and Albiac compare alternate management strategies in two large aquifers located in southern Spain and demonstrate how gains from optimal control may occur when groundwater extraction leads to significant ecosystem damage. They connect the contrast in management outcomes to the different types of policy instruments implemented for each aquifer, and argue that the type of future policy intervention depends on existing management policies. Their results underline the importance of cooperation and collective action for the sustainable management of aquifers when non-extractive values are substantial.

Hansen analyzes the gains from optimal urban groundwater pumping, with demographic and economic characteristics playing an important role, under nine possible future conditions based on assumptions of recharge and water demand growth. The paper further examines the importance of optimal pricing in an urban environment. The results of a numerical case study from Albuquerque, New Mexico (USA) indicate that in the presence of strong demand growth, optimally controlled urban groundwater management and optimal pricing could improve social welfare by more than $20 \%$, extend use of the resource, and provide planners with a mechanism to advance the economic sustainability of groundwater.

\section{Implications of efficiency concepts in water management}

As the era of solving water problems by supply enhancements alone passes, the transition to economically and physically integrated efficiency concepts are best suited to integrated demand-side and supply-side management. Optimal extraction, described in the preceding, corresponds to allocative efficiency which requires that productive resources be allocated to their highest value use. Allocative efficiency implies productive efficiency, which in an irrigation context, requires that the farmer choose the combination of inputs that produces a specified crop yield at the lowest possible cost. Productive efficiency, in turn, implies technical efficiency which requires that more output cannot be produced with the same amount of inputs, thus constraining physical waste of any input. The economic concept of technical efficiency recognizes the physical tradeoffs that exist between all inputs in the production of outputs, as compared to hydrological irrigation efficiency, which focuses on a single key input (water) in isolation from other inputs. Both capital (irrigation technology) and labor (irrigation management) can substitute for applied water in crop production.

Surface water markets are present in many regions of the world as a mechanism to increase the allocative efficiency of water use while addressing environmental or legal constraints. Although groundwater markets could in principle offer many of the same economic and environmental benefits as surface-water markets, they are not common. However, interest in groundwater markets is growing, particularly as enforceable quantification of pumping rights is now occurring in a number of groundwater-dependent agricultural systems worldwide. Skurray and Pannell discuss key issues that must be addressed for successful groundwater transfers. Pitfalls and potential management strategies are illustrated using the Gnangara groundwater system that provides the city of Perth, Australia, with most of its water.

Athukorala and Wilson examine farm-level technical inefficiency in onion production and impacts on groundwater quantity and quality in Sri Lanka. Using a stochastic frontier production function (SFPF), they estimate technical efficiency and the determinants of inefficiency in production. Their results show that overuse of groundwater in onion cultivation decreases yields. They find that most of the efficiency variables are statistically significant and that an appropriate policy instrument could reduce inefficiency.

It is well-known by economists that increasing irrigation efficiency may not save any water, as consumptive use of water may increase even as water application decreases (Caswell and Zilberman 1986; Ward and Pulido-Velazquez 2008). However, development policy in many regions of the world emphasizes subsidized irrigation technology adoption as a mechanism to reduce aquifer depletion rates. Perry and Hellegers use a simple model of groundwater use in Yemen to consider whether increased irrigation efficiency can meaningfully reduce aquifer depletion rates and extend aquifer life. Their analysis illustrates how outcomes depend on how old and new technologies compare in terms of both amounts of water applied to crops and amounts consumed by crops, on quantity of water stock in the aquifer, on what happens to return flows, and on the ability of policy makers to prevent increases in irrigated acreage.

\section{Aquifer viability, stabilization and managed recharge}

Integrated hydrologic-economic modeling offers key insights into how economic incentives interact with groundwater physical processes to determine both short- 
and long-term viability of an aquifer system. However, such models involve multiple kinds of uncertainty that may make it difficult to assess the robustness of policy outcomes. Guillaume et al. present a framework to address different kinds of uncertainty in a dynamic hydrologic-economic model, using the McLaren Vale Prescribed Well area in southern Australia as their example. Their results show how uncertainty analysis can be used to improve the policy-making process, and emphasize ways in which to communicate the importance of uncertainty to policy makers.

Palanisami et al. develop and estimate an empirical model using cross sectional data of tank irrigation systems in Tamil Nadu, India, to advance knowledge on groundwater's stabilization value. Their results indicate that using groundwater adds a $15 \%$ stabilization value beyond the additional value of having greater total irrigation supply. They find that increases in surface-water supply and electricity price reduce groundwater use but increase the stabilization value of groundwater. This increase in stabilization value arises because the forgone benefits at the end of the crop season are higher when the crop is in the fully productive stage and returns per unit of groundwater are high. The authors argue that understanding stabilization value (1) partly explains why millions of relatively poor farmers in South Asia have put more area under groundwater irrigation over the past few decades, and (2) can help in better strategic management of surface and groundwater.

Managed aquifer recharge - the intentional recharge of water to aquifers for future use - is a water-resource management tool of growing importance, particularly in urban areas. Ward and Dillon describe requirements for effective managed aquifer recharge policies. In particular, they consider how to design viable systems for sourcewater harvesting, aquifer recharge, recovery of stored water, and final use. Their focus is on experiences of, and challenges to, managed aquifer recharge in Australia, but they also provide context on policies elsewhere in the world.

\section{Groundwater quality}

Deterioration of groundwater quality has stimulated increased research effort towards quality-management issues. Optimal control of groundwater quality must balance the marginal cost of quality improvements versus the marginal benefits of reduced damages over time. Since remediation of pollutants once in an aquifer is usually prohibitively expensive, the cost-effective policy instrument reflects a tradeoff between reduced loading with potentially long time lags to well locations and treatment of well withdrawals.

Kuwayama and Brozović explore how analytical hydrologic models can inform the effective design and choice of policy instruments to manage groundwater quality. They develop an optimal groundwater-qualitymanagement economic model using analytical solutions from the hydrology literature in a theoretical analysis that characterizes the properties of an optimal emissions policy. Unlike previous economic studies of groundwater contamination, this approach defines optimal emissions policies as a function of geophysical parameters employed by hydrologists such as distance between source and sink, groundwater velocity, and aquifer dispersivity. They demonstrate the relevance of the theoretical results to practical management settings by applying the model to the case of groundwater contamination by chloride from highway deicers to identify effective policy instruments.

Davidson and Wei review studies on past policy attempts to address groundwater-quality deterioration to reveal how difficult the issue is to resolve, and they argue that single disciplinary approaches to groundwater-quality problems will generally not suffice. In a case study of nitrogen leaching on the North China Plain, they demonstrate that increasing the prices of either fertilizer and/or water would have a detrimental economic impact. They argue that the issue of nitrate leaching causing deterioration in groundwater quality is too large and diverse to solve since the farmers most affected will not accept the changes. Thus, they conclude that groundwater contamination in some social contexts can be defined as a 'wicked problem', i.e. complex and unresolvable by applying pure science, closely linked with social issues, and for which there may be no optimal solutions.

\section{Policy in the developing world}

Syme et al. examine the issue of scale in the context of a watershed development policy (WSD) in India that aims to improve the natural resource base and the livelihoods of rural communities through increased sustainable production. The authors argue that practicing WSD policy in an area less than 5,000 ha might be too small-scale and might lead to less than optimal hydrological, economic and equity outcomes. They find that scale in itself is not the only determinant of success since the effect of geographical scale is dependent on the variation in other drivers including hydrological conditions, land use and available institutional structures. The authors caution that results should be interpreted at different levels in the light of interactions between biophysical and socioeconomic scales.

Shah et al. argue that Indian agriculture is trapped in a complex nexus of groundwater depletion and energy subsidies that is the product of past public-policy choices that initially offered opportunities to India's small-holderbased irrigation economy, but now generate many economic, social, and environmental distortions. The authors contend that conventional 'getting-the-price-right' solutions to reduce distortions are consistently undermined by the invidious political economy created by the energygroundwater nexus. They develop simple models of energy-groundwater economics to analyze alternative approaches to minimize the damaging impacts of distortions, highlighting in particular two "second best" 
approaches that Indian policy makers might use as inspiration for a new energy-groundwater policy.

\section{References}

Brown G Jr, Deacon R (1972) Economic optimization of a singlecell aquifer. Water Resour Res 8:557-564

Caswell MF, Zilberman D (1986) The effects of well depth and land quality on the choice of irrigation technology. Am J Agric Econ 68(4):798-811
Gisser M, Sanchez DA (1980) Competition versus optimal control in groundwater pumping. Water Resour Res 16:638642

Koundouri P (2004) Current issues in the economics of groundwater resource management. J Econ Surv 18 (5):703-740

Provencher B, Burt O (1993) The externalities associated with the common property exploitation of groundwater. J Environ Econ Manag 24:39-158

Ward FA, Pulido-Velazquez M (2008) Water conservation in irrigation can increase water use. Proc Natl Acad Sci 105 (47):18215-18220 